\title{
EL CAMEO EN LAS SERIES DE TELEVISIÓN ESPAÑOLAS DESDE UNA PERSPECTIVA DE GÉNERO: UN RECURSO DE NARRATIVA TRANS- MEDIA E INTRAMEDIA
}

\section{Cameo in Spanish TV serials from a gender perspectiva: a resource of transmedia and intramedia narrative.}

\author{
Autoras: DE LARA GONZÁLEZ, Alicia y HIDALGO-MARÍ, Tatiana \\ Doctora - Universidad Miguel Hernández - España - a.lara@umh.es \\ Doctora - Universidad de Alicante - España-tatianahidalgomari@gmail.com
}

\section{Resumen}

La breve aparición de un actor célebre o de una persona relevante representando un papel secundario en una película o serie, es decir, la técnica conocida como cameo, es un recurso narrativo de tipología tanto transmedial (capaz de abarcar múltiples plataformas mediáticas) como intramedial (fomenta las relaciones entre diferentes narrativas dentro del mismo medio) que siempre cuenta con un objetivo promocional. A través de las apariciones estelares de actores, cantantes o presentadores de televisión cuyo programa suele pertenecer al mismo grupo de comunicación en el que se emite la serie, se consigue una autorreferencialidad que conecta dos espacios en beneficio del ente. La presente comunicación analiza, adoptando una perspectiva de género, los cameos que tienen lugar en tres series de televisión españolas y pone especial atención en aquellos protagonizados por mujeres. Por una parte, el trabajo analiza la estrategia autopromocional orquestada a través de los cameos, tanto la que se despliega dentro de la propia cadena como la que alcanza a otros medios. En segundo término, estudia los valores representados en las apariciones de las famosas a través de estas apariciones estelares, que resultan mucho menos significativos que los protagonizados por varones. Concretamente, el total de cameos protagonizados por varones dobla a los protagonizados por féminas.

\section{Palabras clave}

series de televisión, cameos en series de televisión, promoción, género, autorreferencia, transmedia, intramedia.

\begin{abstract}
The brief appearance of a famous actor or a relevant person representing a supporting role in a movie or series, that is, the technique known as cameo, is a narrative device of both transmedia typology (can span multiple media platforms) as intramedial (fosters relationships between different narratives within the same medium) always has a promotional objective. Through appearances by actors, singers or presenters whose program usually belongs to the same channel in the series is issued, a self-referentiality that connects two spaces for the benefit of the network is achieved. This communication analyzes, adopting a gender perspective, the cameos that take place in three spanish TV serials and pays special attention to those featuring women. First, the paper analyzes the selfpromotional strategy orchestrated through cameos, both unfolding within the network itself as it reaches to other media. Second, studying the values represented in the apparitions of women who play cameos, which are much less significant than those by men. Specifically, total cameos featuring the men doubles featuring women.
\end{abstract}

\section{Key words}

$T_{V}$ series; cameos in tv series; promotion; gender, self-reference, transmedia, intramedia. 


\section{Introducción}

El entretenimiento es uno de los objetivos principales de las series de televisión españolas, pero no el único, puesto que poseen también un fuerte componente socializador (Chicharro, 2011, 201). La ficción que se reproduce en las series españolas refleja roles y proyecta conductas que han sido ampliamente estudiadas desde un punto vista tanto educativo (Lacalle, 2011 y PadillaCastillo, 2012) como social (Galán, 2006; Ruíz Collantes, 2006; Cambra, Silvestre y Leal, 2008), o aportando una visión de género y sexualidad próxima a la investigación que aquí se ofrece (Belmonte y Guillamón, 2008; González de Garay, 2009 y Ramírez y Cobo, 2013).

La novedad de nuestro estudio es que el análisis desde la perspectiva de género de las series españolas se centra en la aparición puntual de personajes famosos que provienen de otros espacios o mundos: de otros programas de televisión, del mundo del cine o incluso de la industria musical. Consideramos relevante analizar los cameos de las celebridades televisivas, haciendo especial hincapié en las apariciones femeninas por dos motivos fundamentales. Cuando en las series aparecen personajes famosos que se representan a sí mismos a través de los denominados cameos, se añade un componente de 'realidad ficticia' que agudiza la proyección social televisiva. Además, y según la propia definición de cameo que veremos a continuación, el nuevo personaje es un invitado de prestigio cuya aparición no es casual, sino que está pensada y orquestada para conseguir un objetivo promocional.

Analizar el tipo de personaje femenino que protagoniza el cameo y el mundo del que procede, sus características físicas, el rol que desempeña en la serie y cómo interactúa con el resto de personajes ofrece la posibilidad de extraer los valores asociados a la mujer que la cadena refleja tanto en su contenido imaginario, como en otros tipos de programas más próximos a la realidad. La ficción nacional se convierte en una muestra perfecta sobre la que realizar la investigación por tratarse de "uno de los contenidos clave del prime time internacional y uno de los contenidos preferidos por las cadenas para concitar espectadores frente al televisor" (Diego y Grandío, 2011, 52). Como apunta Chicharro $(2011,202)$, la televisión puede entenderse como un "poderoso medio educativo, que incluso cuando ofrece ficción, distribuye y adoctrina en imágenes sobre los diferentes grupos sociodemográficos y señala patrones de conducta”.

Asumiendo esta concepción, la hipótesis de partida se centra en que los cameos en los que interviene una mujer famosa cuentan con un papel dentro de la serie en el que se le asocia un rol diferente que cuando el cameo lo protagoniza un varón. Aventuramos que en el caso de las apariciones de famosos masculinos a estos les envuelve, en términos generales, cierto halo de protagonismo, se les muestra inalcanzables, mientras que esta cualidad se echa en falta en el caso de las apariciones femeninas, más relacionadas con lo mundano o lo frívolo.

Desde el plano publicitario, se intuye que en la mayoría de los casos los cameos tienen un objetivo autopromocional: el famoso o famosa es, en algunos casos, un personaje que proviene del mundo audiovisual y que trabaja para la propia cadena. De esta manera, el ente utiliza la serie para promocionar otros espacios y al famoso para promocionar la serie. Cuando el famoso tiene un espacio en la narración se crea un puente realidad-ficción que contribuye a construir un todo programático que se nutre de sí mismo a través de una estrategia de continuidad. El cameo se convierte entonces en una técnica autorreferente asociada con el branded televisivo y con el concepto de transmedia e intramedia storytelling. Transmedialidad porque se dan casos en los que un personaje del mundo del cine, como puede ser el actor José Coronado se interpreta a sí mismo en un capítulo de la serie, en una trama en la que se graba una película para la gran pantalla. Se crea un puente entre ambos medios (cine y televisión) en el que las referencias a uno y a otro son mutuas. Mientras que la intramedialidad, más abundante, la encontramos en aquellos casos en los que el personaje que protagoniza el cameo proviene del ámbito televisivo, casi siempre de la misma cadena, por ejemplo el caso de presentadores que aparecen en uno de los capítulos, interpretándose a sí mismos y desplegando, dentro de la serie, el reality show que conducen en la no ficción. El concepto de intramedialidad, lo aplica recientemente Harvey (2012: 65) en su estudio sobre la crossmedia en 
dos series americanas: The Green Hornet y Doctor Who, para referirse a casos en los que la narración fluye entre distintos espacios (la serie y el programa posterior en el caso descrito por Harvey) dentro del mismo medio, el televisivo en esta ocasión.

Como explica Scolari (2009) en su análisis descriptivo de la estructura de textos multimedia creada en torno a 24 series de la cadena Fox, el concepto de transmedia storytelling fue introducido por Jenkins en 2003. En un nivel básico, se trataría de historias contadas a través de diferentes medios. Para Scolari $(2009,600)$, en la actualidad el concepto ha evolucionado y los textos tienden a fluir a través de múltiples plataformas, de tal manera que la transmedialidad no solo afecta al texto, sino que además incluye transformaciones en la producción y en el consumo.

\begin{abstract}
"Transmedia storytelling is a narrative that includes a series of stories expressed through different media. This narrative articulates an expression (TV serials, comics, video games, etc) with a hierarchy of values that act as the content of the fictional world. These values are expressed in all the different texts that integrate the space of a certain transmediastorytelling experience" (Scolari, 2009, 600).
\end{abstract}

La convivencia y retroalimentación de los contenidos entre diferentes plataformas que se da en el cameo fomenta que la construcción social de la mujer encuentre aquí una triple vía de estudio: 1) el desempeño profesional de la mujer fuera de la ficción, por el que es elegida para su aparición estelar; 2) su desempeño interpretativo, en tanto actriz, aunque sea amateur y 3) el rol que asume en la ficción, el tono de su intervención, la situación narrativa en la que hace aparición y su interacción con el resto de personajes.

\section{Metodología}

La metodología parte, en primer lugar, de una revisión bibliográfica y una acotación del alcance del término 'cameo'. En el trabajo de campo se ha distinguido entre 'cameo' y 'colaboración', término este último que las propias series utilizan en sus créditos para referirse a la aparición de un personaje en más de un capítulo, pero sin llegar a formar parte del elenco de la serie. Se ha optado por tener en cuenta ambos tipos de apariciones porque a efectos de nuestro análisis, tanto en términos autopromocionales como de género, no existen diferencias más allá de la prolongación de las apariciones.

Se ha llevado a cabo un análisis cuantitativo y cualitativo de los cameos y colaboraciones que han tenido lugar en tres series de televisión españolas: Aída (Tele 5), Fenómenos (Antena 3) y Cuéntame cómo pasó (TVE1), durante las temporadas de 2012 y 2013. Se construye una comparativa centrada tanto en la forma de utilizar el recurso, como en el estudio de los diferentes valores e identidades reflejados desde una perspectiva de género.

Se ha seleccionado una serie de cada una de las tres cadenas con más audiencia, según el Estudio General de Medios publicado el 9 de febrero de 2014, sin tener en cuenta la audiencia del conjunto de cadenas temáticas. La muestra se compone por tanto del visionado de más de 120 capítulos entre las tres series, en los que se han contabilizado más de 40 cameos o colaboraciones. El conjunto de cadenas temáticas encabezan el ranking del EGM (febrero de 2014) con un $22,7 \%$ de cuota de pantalla. Tras ellas aparece Antena 3 que con un 17,2\% de share supera a Telecinco (17\%). Les sigue TVE1 con un 13,2\%.

Tabla 1: Número total de capítulos y cameos según serie.

\begin{tabular}{|c|c|c|c|}
\hline & $\begin{array}{c}\text { Total } \\
\text { capitulos } \\
12-13\end{array}$ & $\begin{array}{c}\text { Total } \\
\text { cameos } \\
\text { /colaboraciones }\end{array}$ & $\begin{array}{c}\% \text { cameos } \\
\text { respecto a } \\
\text { capitulos }\end{array}$ \\
\hline Aida & 61 & 14 & $22 \%$ \\
\hline Fenómenos & 9 & 22 & $244,44 \%$ \\
\hline Cuéntame & 60 & 14 & $23 \%$ \\
\hline TOTAL & 130 & 50 & $38,46 \%$ \\
\hline
\end{tabular}

Fuente: Elaboración propia

Los parámetros tenidos en cuenta en el análisis del contenido audiovisual están relacionados con los objetivos que persigue la investigación, ya se trate del análisis desde el punto de vista de la autopromoción televisiva, como de los valores representados por los famosos que protagonizan los cameos. En términos cuantitativos se ha tenido en cuenta, aparte de la cadena concreta y la fecha de emisión (2012-2013), el 
número total de capítulos visionados de cada serie y el total de cameos. El objetivo ha sido obtener el porcentaje de apariciones puntuales de famosos respecto al total de capítulos en las dos temporadas de cada serie analizada. Se han registrado y analizado todos los cameos, tanto los femeninos como los masculinos, con el objetivo de poder establecer las diferencias existentes entre ambos. Asimismo, se ha extraído el número total de cameos en los que el personaje que lo protagonizaba pertenecía al mundo televisivo, con el objetivo de determinar el total de paratextos intramediales detectados.

Los parámetros cualitativos analizados han sido, en primer lugar, el personaje concreto que protagoniza el cameo, ya se trate de un hombre o de una mujer y, en segundo lugar, su procedencia, es decir, si proviene del mundo televisivo, del cine o de otro ámbito popular. Con la meta de analizar el componente autorreferencial, se ha especificado si el personaje famoso está relacionado con la cadena concreta que emite la serie, es decir, si pertenece a otro programa emitido por la cadena o no. Y si durante la representación de su papel promociona de forma explícita a la propia cadena o a otro contenido emitido por ésta.
De la misma manera, se ha tenido en cuenta el rol proyectado por el personaje desde diferentes perspectivas:

1. El rol temático: Se establecen dos categorías para clasificar a los personajes dependiendo de su convergencia familiar o profesional en el marco de la estructura narrativa

2. El rol semiótico. De acuerdo a la propuesta de Greimas (1972: 45-86) que clasifica a los personajes del relato no por lo que son, sino por lo que hacen, se propone establecer dos categorías: si el personaje representa un papel considerado como 'malo' porque lleva a cabo conductas en las que se reflejan rasgos negativos claramente reprochables o 'bueno', cuando el personaje lleva a cabo conductas consideradas beneficiosas o positivas en el contexto de la serie.

Por último, se han incluido dos parámetros relacionados con la imagen física del famoso, concretamente observando si su aspecto se corresponde o no a los cánones de belleza actuales y su edad de acuerdo a tres franjas: menor de 25, entre 25 y 45 años y mayor de 45 .

\section{El cameo como recurso autorreferente que rompe los estándares de la ficción}

Sorprende la escasez de estudios centrados en los cameos (en el caso de España prácticamente inexistentes), a pesar de tratarse de una técnica narrativa audiovisual extendida en las series de televisión tanto de producción nacional como internacional. Aunque el término no está recogido en el diccionario de la Real Academia de la Lengua Española, se trata de un concepto ampliamente difundido. El catedrático de Lengua y Literatura José María Romera explica en su blog Las Palabras de la Tribu que el término se introdujo en el mundo del cine importado del inglés:

\footnotetext{
"Se llama 'cameo' a la aparición breve de un actor célebre o de una persona relevante representando un papel secundario, generalmente como guiño de complicidad que ayuda a promocionar la cinta. (...) Cuando hablamos, pues, de 'cameos' en el cine, el teatro o la televisión, evocamos una imagen en miniatura que, a la vez que representa a alguien querido o respetado, ennoblece a quien hace exhibir esa figura".
}

En esta definición se aprecia cómo el concepto de cameo está fuertemente asociado a la promoción de la propia serie o cinta, de manera que aparte de ser un recurso narrativo más o menos original, se incluye dentro de las posibilidades de explotación comercial de las series familiares, puesto que la aparición estelar de este $\mathrm{u}$ otro personaje no es casual. La presencia de la celebridad esconde una finalidad concreta: la promoción del propio personaje, la de un producto, una película, un disco o la de otro programa de la propia cadena. En este último caso, la técnica se convierte en autorreferente, ya que se "emplaza" al famoso para volver sobre la cadena sin haber salido de ella. Se crea un puente entre la ficción y la realidad televisiva, a través de lo que se podría denominar “celebrity placement”. El cameo se convierte en una forma sutil de hacer autopublicidad, una publicidad ínsita en el propio contenido narrativo, como un distintivo característico de la propia promoción de las industrias de los medios y cadenas. De esta manera, la 
cadena, como soporte publicitario televisivo, se convierte en un sitio privilegiado para autopublicitarse. Como señaló Andrew Wernick (1991, 1 00-101):

"In the case of cultural commodities, that is those goods where what is consumed (no more nor less) is the signifying material they contain, the mediatized promotion for the product is delivered by the same means, that is by the same channels of communication, as those which deliver the product itself. The promotional reflexivity which this implies goes beyond the mere fact that actual ads for newspapers, magazines, films, records, TV shows, etc, are carried -like those of non-cultural goods- in that same range of media. [...] A distinctive feature of the media industries' own promotion $[\ldots]$ is that the product which they have to advertise is a privileged site for the advertisement of itself".

Las apariciones ocasionales de famosos en series o películas se construyen a través de una llamada a la realidad desde la ficción en la que el famoso puede actuar de sí mismo. Esta técnica constituye como veremos una práctica en la ficción televisiva más habitual de lo que a primera vista pudiera parece (Van Heerden, 1998) y desde el punto de vista semiótico se enmarcaría dentro de lo que García Martínez (2009: 655) considera "estrategias metaficticias": recuerdan al espectador que se encuentra ante un discurso capaz de desvelar su propia condición de artificio. Estas apariciones estelares de los famosos que se asoman a la ventana de la ficción, como las propias series en las que aparecen (Medina, 2001: 51), contribuyen a fomentar los valores de identidad de la cadena y los transportan a otra dimensión. El rol que irradia el famoso en su ámbito habitual se extiende a otros espacios, aunque el perfil de espectador o el horario de emisión varíen. Se trata de una técnica especialmente potente en términos de autopromoción porque se fundamenta en la conexión de la ficción con la realidad: "Con la autorreferencialidad se asciende un peldaño en la ruptura del espejo ficcional, emborronando aún más para el espectador las relaciones entre realidad y ficción" (García Martínez, 2009: 660).

Dentro de los diferentes paratextos que se pueden generar en torno a una serie de televisión, el cameo forma parte de los paratextos corporativos, es decir, creados por la propia cadena, en contraposición a los no corporativos, originados por los fans y la audiencia y sobre los que el programa pierde el control (Hardy, $2011,8)$. En este grupo de textos "controlados" también se encontrarían acciones de relaciones públicas y determinadas estrategias de marketing, lo que se traduce en tráileres publicitarios, tonos para el teléfono móvil o fondos de escritorio con las estrellas de la serie. Un abanico de posibilidades que, como explica Hardy $(2011,8)$, basándose en su estudio sobre las series e HBO, se extiende a lo largo de un espectro de mayor a menor control sobre el discurso comercial.

Pero a diferencia de la publicidad convencional, el cameo forma parte de la narración, está integrado en la serie y comparte con ella características artísticas al formar parte del guión. Y no de una manera estática, como ocurre en el branded placement -"presencia de marcas comerciales en un contexto audiovisual, literario o musical", según Del Pino (2006)- sino viva y que interactúa con los protagonistas y les influye. En este sentido, conviene hacer hincapié en el hecho de que la proliferación de los cameos, como en el caso de otros ejemplos de publicidad no convencional insita en un medio convencional, por ejemplo las imágenes de archivo o las menciones entre programas, se utiliza en buena medida para contrarrestar la saturación publicitaria a través de técnicas más sutiles y efectivas, pero también para establecer un flujo continuo que emborrona los límites entre los diferentes programas:

\footnotetext{
"La cadena se nutre de sus propios contenidos y genera un flujo continuo de referencias a ella misma que avanza entre los diferentes programas, hasta el punto de que cuesta distinguir unos de otros porque muchas de las imágenes e informaciones son las mismas" (De Lara, Rodríguez y Sánchez, 2013).
}

Asimismo y para liar un poco más la madeja de la transmedialidad definida por Jenkins (2006: 20-21) y actualizada por Scolari (2009), los cameos, aparte de en la promo de la serie, también se anuncian en otros espacios, por ejemplo, en las webs de las cadenas, donde generan comentarios por parte de la audiencia. Estos sitios web son un ejemplo perfecto de lo que Brooker (2003: 323) describe como "desbordamiento televisivo", donde las productoras construyen "una experiencia de estilo de vida en torno a un texto básico, utilizando el Internet para ampliar el compromiso público y fomentar una interacción de dos vías" (Perryman 2008, 29). Pero también les aproxima al concepto de construcción social: "La identificación con los personajes contribuye a incrementar la fidelidad de la audiencia y es el rasgo fundamental para garantizar ventas posteriores del programa en las diferentes ventanas de explotación" (Medina, 2007, 60). Como ejemplo, la serie La que se avecina de Tele 5 puso en marcha en diciembre de 2013 un concurso 
promocionado por la web de la cadena en el que regalaban un cameo en uno de los capítulos de la octava temporada al telespectador ganador que contestara una serie de preguntas sobre los personajes. Se trata de un ejemplo de transmedialidad en el que se fomenta no solo la participación del espectador desde su sillón, sino que se le llama a ser parte de la historia, convirtiendo la aparición en el relato en un premio. La cadena consigue así fomentar la participación del fan de la serie a través de los diferentes medios. Como apunta García Mirón (2012: 74), Internet se convierte en "un parámetro estratégico para las campañas de posicionamiento o fidelización de la audiencia hacia sus contenidos".

Vemos como las webs de las cadenas se convierten en un elemento clave a la hora de expandir y desdoblar las narrativas, suponen un salto cualitativo en comparación con los contenidos off line, donde el espectador solo se limita a la mera recepción. "El soporte televisivo no permite dicha interacción, aspecto que queda superado en las nuevas plataformas on line de las series de televisión españolas" (Rodríguez y Gallego, 2012: 119).

Otro ejemplo de transmedialidad televisión-Internet que se fundamenta en la técnica del cameo lo encontramos cuando días previos a la emisión del capítulo de la serie Aída en la que realiza un cameo la presentadora María Teresa Campos, se lanzó en la web del grupo Globomedia un vídeo en el que la presentadora animaba a que los espectadores vieran el capítulo el siguiente domingo. En este caso es desde la página web donde la presentadora avanza su participación en el capítulo televisivo a través de un paratexto publicitario en el que narraba lo divertido que había sido el rodaje. Ya no el propio cameo, sino su producción, crean un puente entre ambos medios, siempre bajo el objetivo promocional tan característico del cameo como de la propia crossmedia strategy que Scolari (2012: 7) relaciona con una estrategia de diversificación económica:

\footnotetext{
“ (...) attempts by right' holders to creatively adapt their property for a variety of media platforms, in order to either obtain a higher margin from that property, or strengthen it via cross-promotion among platforms".
}

\section{La construcción social de la mujer en las series de televisión españolas a través del cameo}

Que el texto no es plano, sino que dispone de distintos niveles de significación, es un hecho contrastado y estudiado que nos permite entender que el discurso, al fin y al cabo, contiene ideología (Van Dijk, 2008). Partiendo de esta premisa, entendemos que la representación de la mujer en los discursos narrativos, en concreto en las series de televisión, contienen una fuerte ideología representativa capaz de transmitir valores sociales, positivos o negativos, acordes o no a la realidad social del momento pero, de una manera o de otra, comunicativos.

Ya en los ochenta se estableció que los discursos televisivos ejercen un papel fundamental en la representación y transmisión de roles sociales (Gerbner et al., 1980; Gerbner, 1998; Lauzen, Dozier y Horan, 2008; Glascock, 2001) y que estos contenidos televisivos suponen un factor determinante en la construcción de identidades sociales, en especial en la construcción social de la mujer. Aunque cada vez son más las ficciones que contemplan el género femenino desde una igualdad social (en especial con la representación de la mujer trabajadora), aún suele prevalecer la representación del orden doméstico o la similitud de roles temáticos. Tal y como establece Galán (2007): "Los estereotipos femeninos que se representan en la ficción televisiva responden a los arquetipos de género tradicionales asociados al mundo de las emociones".

La representación femenina en el seno de las narrativas intra y transmediáticas precisa de una lectura de género, si tenemos en cuenta el poder del producto cultural a la hora de contribuir a la transmisión de valores sociales. Esta representación femenina, basada en el estereotipo, por ser éste el instrumento efectivo de representación de modelos en la narrativa televisiva, no puede obviar la simplificación de la realidad y la resistencia al cambio. El problema, analizado desde la perspectiva de género, es que con frecuencia la 
simplificación que conlleva la utilización de estereotipos no puede separarse de los prejuicios de género, hecho que evidencia la función ideológica del estereotipo (Garrido, 2001: 331-346).

$\mathrm{Si}$ acotamos la relación entre el discurso intra y transmediático y la representación femenina bajo el formato del cameo, debemos afirmar que ésta supone una representación más bien publicitaria, aunque forme parte de la narración y comparta con ella la esencia del contenido, el mensaje y el contexto de las historias. El cameo, por tanto, contribuye a contarnos la historia, aunque sin abandonar en ningún momento su objetivo promocional. La imagen femenina está doblemente representada a través de este recurso publicitario y narrativo. Una polifuncionalidad en dos órdenes distintos de la significación: como actriz o actor que desempeña un rol narrativo que interactúa con el resto de personajes de la serie y, por otra parte, como persona que aparece en otros programas de la cadena, o en películas de cine o viene del mundo del espectáculo. Mundos a los que remite, rompiendo, como explicaba García Martínez (2009: 660), el pacto ficcional. De esta manera, el cameo tiene una serie de consecuencias en la puesta en escena de la mujer y en su contribución a la construcción social de género. Si tenemos en cuenta que el cameo transmite una realidad externa a la narración, pero que se integra en su propio discurso, podemos leer que:

\footnotetext{
"Las series dramáticas integran verdaderos discursos de realidad y están formadas por pequeños fragmentos que pretenden constituirse como un espejo de la misma, ya que transmiten modelos de conducta, prejuicios, valores y toda una serie de comportamientos sociales" (Galán, 2007).
}

\section{Análisis de resultados}

Con el fin de establecer de qué manera se utiliza el cameo desde el punto de vista de la autorreferencialidad y haciendo especial hincapié en la representación de la imagen femenina, se ha procedido a la recogida de datos siguiendo tres ejes fundamentales: en primer lugar, desde un punto de vista comparativo entre la presencia y uso de esta forma autopromocional entre ambos sexos, en segundo lugar, desde un punto de vista de la promoción, la autorrepresentación y las vinculaciones promocionales del recurso y, en tercer lugar, desde una perspectiva estética y del discurso, teniendo en cuenta los roles temáticos y semióticos que asumen los personajes de la muestra. En la tabla número 2 quedan representadas las dos variables de nuestro estudio en términos totales y según cada serie analizada:

\section{Tabla 2: Cameos según género e intramediali- dad.}

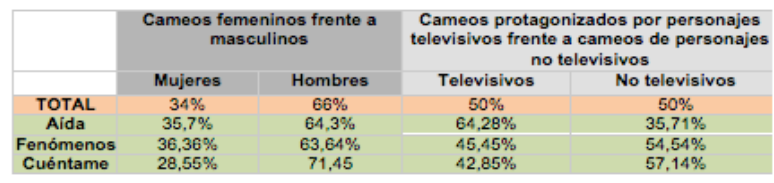

Fuente: Elaboración propia

En las tres series analizadas, la representación femenina en formato cameo o colaboración especial ocupa alrededor del $30 \%$ de los casos detectados; reservándose en un $66 \%$ de media a las apariciones especiales masculinas, frente a un $34 \%$ de media para los cameos protagonizados por féminas. Es decir, el total de cameos masculinos dobla de forma holgada a los femeninos, dos tercios del total, frente a un tercio. Estos datos, que a priori son meramente descriptivos, nos permiten avanzar que la representación de la mujer desde el punto de vista promocional es inferior a la presencia masculina.

Respecto a la trans e intramedialidad se observa que los porcentajes están repartidos de manera equitativa: 50\% para casos en los que el personaje proviene del mundo televisivo (ejemplos como Susanna Griso, Jesús Vazquez, Carlos Sobera, María Teresa Campos...) y $50 \%$ para aquellos casos en los que el famoso proviene de otras industrias, en las que destacan la cinematográfica (por ejemplo José Coronado, Natalie Pinot, Santiago Segura, Terele Pávez...), la musical (Carlos Baute, El Koala, Pablo Alborán, Dani Martín...) y el mundo del deporte (Fonsi Nieto, Alberto Contador, Carlos Moyá...). Es importante destacar que aunque el reparto sea del 50\% para los dos casos, el total de personajes televisivos, y por lo tanto intramediales, resulta más representativo porque iguala al del resto de industrias agrupadas. De esta manera es posible señalar que existe una importante autorreferencialidad mediática. Y del estudio sobre las 
tres series analizadas podemos deducir que el medio televisivo se nutre de sí mismo en la mitad de los casos en los que introduce un cameo.

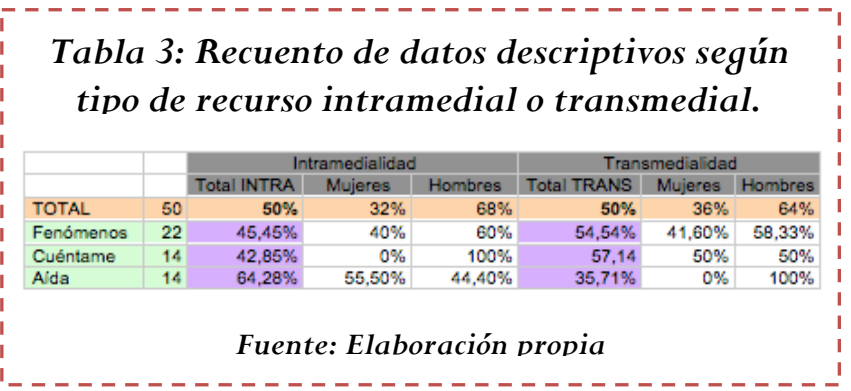

En la tabla número 3 se recogen los datos descriptivos relativos a la procedencia del personaje que protagoniza el cameo, según género y serie. Este recuento nos permite visualizar la diferencia porcentual entre los cameos cuya procedencia es el mundo televisivo y, por tanto, asumen la clasificación intramedial, frente aquellos que provienen de otros medios o industrias (cine, música, mundo deportivo....) y a los que hemos clasificado como transmediales. Los resultados nos muestran que existe total equilibrio entre los personajes del propio medio frente a los de otros medios (representando el reparto al 50\%). No obstante, sí que detectamos diferencias entre el uso de estos recursos en una serie y en otra: El recurso transmediático es, a priori, más recurrente, como podemos observar en el caso de Fenómenos y de Cuéntame, aunque sigue existiendo un porcentaje elevado de casos intramediáticos. La serie Aída, por su parte, da mucha más importancia al recurso intramedial utilizándolo en un $64,28 \%$ del total de los cameos analizados, frente el $35,71 \%$ que destina a casos transmediales.

$\mathrm{Si}$ analizamos estos resultados desde una perspectiva comparativa entre hombres y mujeres, observamos que no existen diferencias notables, al margen de la mayor presencia de hombres en ambos recursos (tanto transmedia como intramedia). El caso concreto más relevante sería el porcentaje superior de mujeres que representan el cameo intramedia en Aída $(55,0 \%)$ frente al $44,40 \%$ de hombres y la inexistencia de mujeres en el recurso transmediático de la misma serie. Cuéntame, por su parte, representa equidad en el recurso transmediático pero no utiliza ninguna presencia femenina en los ejemplos intramediales. Fenómenos es la serie que mayor equilibrio presenta tanto en casos intramediales como en transmediales, aunque sobresale levemente la figura del hombre en ambos casos.

\section{Tabla 4: Datos sobre autorrepresentación y} promoción.

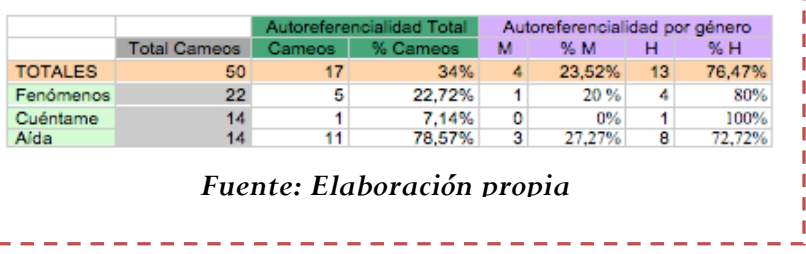

Los datos obtenidos de la tabla 4 nos confirman que, del total de cameos registrados, solo un 34\% asume la función de la autorreferencialidad, es decir, se interpreta a sí mismo durante su aparición en la serie y, por lo tanto, contribuye de una manera explícita a la promoción de su propia imagen y contribuye a romper los estándares de la ficción. Ante estos términos generales, la serie Aída es la que más importancia otorga a este fenómeno, ya que lo registra en un $78,57 \%$ del total de cameos analizados, seguida de Fenómenos, que lo utiliza en un $22,72 \%$ de sus casos y la serie Cuéntame, en la que autorreferencialidad es prácticamente inexistente en el cameo y sólo se detecta en un 7,14\% de los casos.

La autoreferencialidad del personaje, tal y como nos muestran los datos de la tabla anterior es mucho más exitosa en el caso de los hombres que en el de las mujeres. Podemos observar que el porcentaje de mujeres que se autorrepresentan a ellas mismas en las series analizadas es escaso en Fenómenos, representando un $20 \%$ frente al 27,27\% de Aída de Telecinco. En el caso de Cuéntame el cameo desde el punto de vista de la autorrepresentación en mujeres es inexistente debido, sin duda, al carácter histórico de la serie, en la que resulta imposible que el personaje aparezca como real en un escenario histórico que pertenece a otra época. En el caso de los hombres, la autorrepresentación ocupa un $80 \%$ en el caso de Fenómenos frente al 72,12\% de cameos masculinos que se autorepresentan en Aída. El caso de Cuéntame sigue siendo el más irrelevante desde el punto de vista de la autorrepresentación ya que solo lo detectamos un caso en el que existe la autorepresentación y se le atribuye al $100 \%$ a una figura masculina. 
Podemos observar que, mientras la autorrepresentación adquiere mucha importancia en la serie de Telecinco, Aída, en el resto de series analizadas no se entiende como un elemento recurrente. La autorrepresentación en Aída, en términos globales, es utilizada en el $78,58 \%$ de las representaciones especiales/cameos analizados. De la misma manera que en esta serie se han contabilizado un total de 14 referencias explícitas a otros espacios de la cadena. No obstante, estos datos se vuelven menos relevantes en el caso de Antena 3 y la serie Fenómenos, en la que sólo un $23,72 \%$ de los cameos detectados se autorrepresentan a sí mismos (y se detectan 4 referencias explícitas a otros espacios de la cadena) y prácticamente nulos entre los resultados obtenidos de Cuéntame (ninguna referencia explícita a otro espacio de la propia cadena). Como adelantábamos, una causa probable de esta carencia en la serie de la cadena pública puede ser el hecho de que se trata de una serie de corte histórico, de manera que no resulta fácil de encajar con el propio guion la aparición de personajes mediáticos actuales, teniendo en cuenta que la primera cadena empezó sus emisiones regulares a mediados de los años sesenta.

Estos datos coinciden con el estudio sobre los contenidos autorreferenciales detectados sobre la programación diaria de estas tres cadenas, llevado a cabo por De Lara, Rodríguez y Sánchez (2013). En este trabajo realizado sobre 24 horas de emisión se refleja que de las tres cadenas analizadas, Tele 5 es la que más explota la autorreferencialidad con más de 5 horas diarias. Antena 3 emite casi 2 horas al día, mientras TVE1 incluye más de 3 horas diarias de autocontenidos. En nuestro estudio es también la serie de Tele 5 Aida la que muestra un mayor número de cameos en los que el personaje se autorrepresenta dentro del capítulo, creando esa conexión entre espacios de la misma cadena, como parte de la estrategia autopublicitaria del ente.

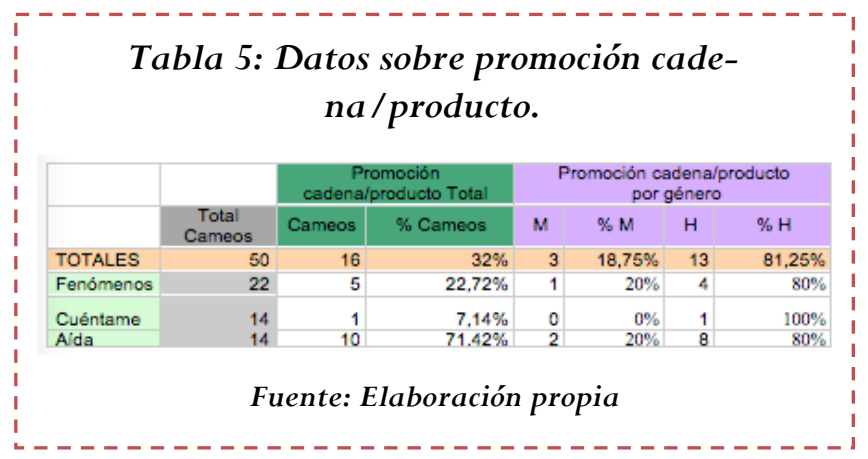

Siguiendo con el uso promocional del cameo, debemos destacar que la alusión por parte del personaje real a la propia cadena o a algún producto en concreto se detecta en un 32\% del total de casos analizados. En la mayoría de casos prima más la integración del personaje dentro del seno de la narración por encima de su vinculación con el mundo real y, también, por encima de su propia función emisora o prescriptora. En este apartado detectamos una importante infrarrepresentación de la mujer que apenas en un 6\% de los casos analizados asume el rol de prescriptora de un producto o la propia cadena. Los hombres, por su parte, asumen el rol publicitario en un $26 \%$ de los casos analizados, siendo la serie Aída de Telecinco la que más relevancia otorga a este recurso promocional, coincidiendo con la mayor autorreferencialidad demostrada en la tabla anterior también por la serie de Tele 5 .

Uno de los ejemplos en el que la mujer asume el rol de prescriptora desde el cameo lo encontramos en la aparición de Susanna Griso - presentadora de Antena 3en la serie Fenómenos de la misma cadena, en el capítulo del $04 x 1$ - en la que la presentadora se autorrepresenta a ella misma como profesional del sector y, de manera metatextual promociona no solo el propio enclave de la cadena emisora y sus decorados y escenarios, sino el programa Espejo Público que presenta diariamente en la cadena en cuestión. La serie Aída nos deja otro ejemplo promocional de la mano de un personaje femenino en el capítulo 1x10, interpretado por Raquel Sánchez, presentadora también de Telecinco, del programa Perdidos en la tribu. La presentadora aparece en dos capítulos, se introduce en la serie en calidad de sí misma, es decir, como presentadora del programa y traslada espacios reales de su reality show dentro de la narración ficticia, ya que es el elenco de la serie quien participa en este programa de supervivencia.

Desde esta perspectiva, la serie Cuéntame no aporta ninguna información, ya que no existen vinculaciones con la autopromoción ni de la cadena ni de productos añadidos. Este hecho lo atribuimos al carácter histórico de la serie que limita en cierta manera las posibilidades de explotación en este sentido, como comentábamos en párrafos anteriores.

Siguiendo con el análisis de los cameos y su puesta en escena en el seno de la narración, consideramos conveniente aproximarnos al rol que asumen los 
colaboradores en sus intervenciones puntuales. Este aspecto es importante para conocer el mensaje que, independientemente de su autorrepresentación o representación ficticia, se transmite mediante el personaje colaborador.

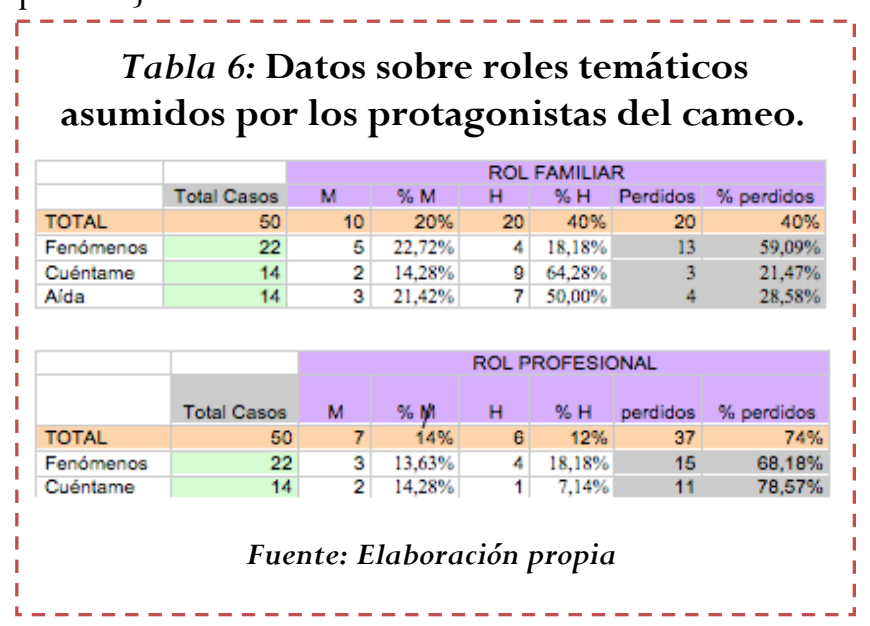

Según los datos reflejados en la tabla anterior, el rol familiar es asimilado frecuentemente por los personajes que intervienen a modo de cameo, reservando un $40 \%$ de casos que asimilan este rol a los hombres, frente al $20 \%$ que asumen las mujeres. Resulta relevante señalar que existe un $40 \%$ de casos perdidos o neutros, en los que los personajes que intervienen mediante la fórmula en cuestión no presentan rasgos que nos permitan atribuirle el rol familiar.

La serie Aída es la que, con diferencia, más referencias al rol familiar aporta a los hombres, mientras que Fenómenos da más notoriedad da a las mujeres en este sentido, representando un 22,73\% de los casos analizados. Cuéntame, por su parte, trasmite el rol familiar en los hombres en un 64,29\%, hecho que resulta curioso si tenemos en cuenta el contexto sociocultural en el que se desarrolla la acción. Algo que puede deberse a que las dos temporadas de la serie que se han tenido en cuenta en el análisis responden a un periodo de la historia española en el que había una mayor apertura (finales de la década de los setenta, principios de los ochenta) y precisamente la serie quiere mostrar ese ascenso de la mujer a puestos de trabajo.

Sin embargo, observamos que, en términos generales, los porcentajes de encuadre de la mujer en el rol familiar son mayores que en el profesional en Fenómenos y Aída, mientras en Cuéntame coinciden los porcentajes. Teniendo en cuenta este dato, podemos afirmar que, como en el caso del estudio llevado a cabo por Bernardo, Pellisser y Aguilar (2009) sobre la serie La Alquería Blanca, también con los cameos aparecidos en las series estudiadas se fomenta el imaginario social patriarcal en el que el rol profesional está más representado por los varones.

En este sentido, debemos destacar la relevancia de que aunque en la serie Fenómenos la asimilación del rol profesional por parte de la mujer sólo se aprecia en un $13,63 \%$ frente a un $18 \%$ masculino, en el resto de series, las colaboraciones femeninas que asumen un rol profesional son mayores.

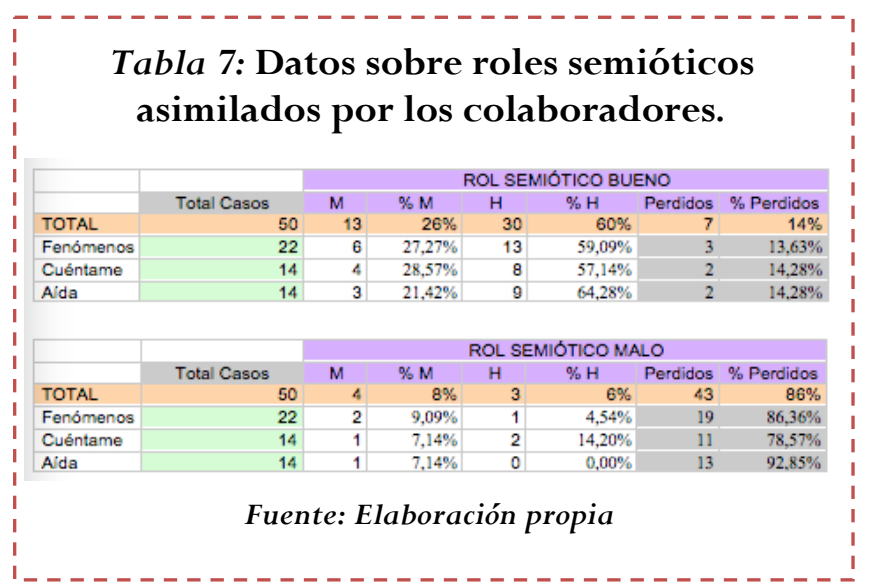

Si comentamos el rol semiótico que asumen los personajes analizados, observamos que la mayoría de ellos proyectan un rol semiótico 'bueno', de acuerdo, como exponíamos en el apartado metodológico, a una valoración global de las acciones que lleva a cabo en la historia. No obstante, existen diferencias notables entre hombres y mujeres. Como se refleja en la tabla número 7 , el 60\% de los hombres analizados asume este rol de una manera global, mientas que solo alrededor de un $26 \%$ de las mujeres manifiesta a través de las acciones que lleva a cabo su rol semiótico 'bueno'. Esta diferencia augura que, de alguna manera, la figura masculina se relaciona con lo positivo en términos generales de una forma más contundente, mientras que la mujer no asimila de forma genérica este rol, sino que sus acciones en este sentido son más cambiantes a lo largo del discurso narrativo.

El porcentaje de personajes que asumen el rol semiótico 'malo' es realmente escaso, si tenemos en cuenta que existe un $86 \%$ de casos perdidos o no pertinentes, a los que no se les puede atribuir dicho rol temático. Aunque no adquieran relevancia porcentual, centrándonos en los casos favorables, debemos destacar 
que existe sobrerrepresentación de la mujer en este sentido, con un $8 \%$ del total frente a un $6 \%$ representado en hombres. El caso que se muestra contrario en esta ocasión es Cuéntame, serie en la que casi un $15 \%$ del total de hombres analizados asume el rol de malo, frente a un 7\% de mujeres. Entendemos que las vinculaciones históricas y políticas de la serie contribuyen a esta representación negativa del hombre, que en el contexto de esta ficción se mueve entre problemas políticos, tramas corruptas y problemas socioculturales. La representación de la mujer mala no supera el $10 \%$ en las otras dos series analizadas pero la tendencia global sí es mayor que la de los varones.

En cuanto a la puesta en escena, hemos contemplado dos variables esenciales: su aspecto físico y su edad, con el fin de detectar las diferencias fundamentales entre hombres y mujeres teniendo en cuenta su representación física.

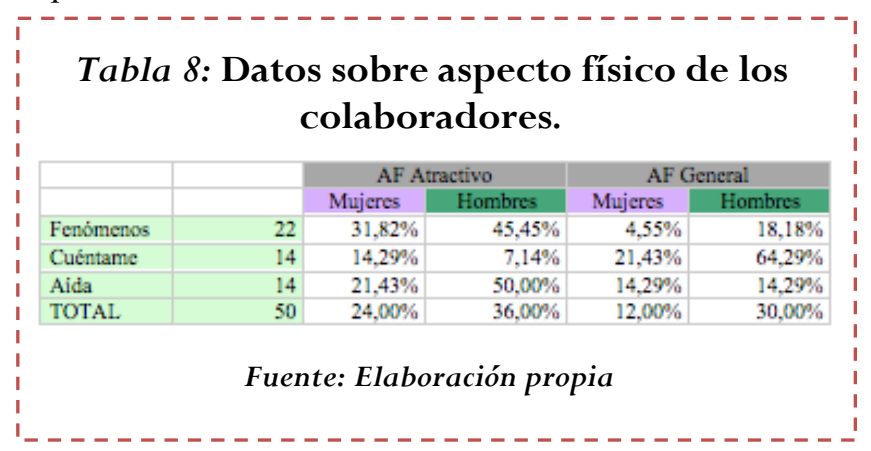

Si tenemos en cuenta el aspecto físico de los personajes representados en los cameos, observamos que, por lo general, aparecen personajes que se aproximan a los cánones de belleza actuales, sobre todo en el caso de los hombres. De la misma manera que no se han detectado casos que se sitúen al otro extremo del concepto de belleza actual en ninguno de los dos géneros. Las mujeres asumen en un $24 \%$ del total de casos analizados un aspecto atractivo y en un $12 \%$ un aspecto general y los hombres equiparan más su presencia con un 36\% y un 30\% en cada estilo.

Los resultados concretos varían dependiendo de la serie. En el caso de Aída destaca por ser de las tres, la serie en la que la diferencia entre el aspecto físico atractivo de los hombres en comparación con el de los cameos femeninos es más notable: $50 \%$ frente a $21 \%$. En Fenómenos es donde vemos que la diferencia entre sexos es menor: $31 \%$ frente a $45 \%$. Cuéntame, por su parte, representa más mujeres con un aspecto general $(21,43 \%)$ que con un aspecto atractivo $(14,29 \%)$, dato probablemente justificado por la necesidad del guión en la transmisión de sencillez y valores más generales.

\begin{tabular}{|c|c|c|c|c|c|}
\hline \multicolumn{6}{|c|}{$\begin{aligned} \text { Tabla 9: Datos sobre edad de los } \\
\\
\text { colaboradores. }\end{aligned}$} \\
\hline & & AF A: & ctivo & $\mathrm{AFC}$ & neral \\
\hline Fenómenos & 22 & $\begin{array}{l}\text { Mujeres } \\
31.82 \%\end{array}$ & Hombres & $\begin{array}{l}\text { Mujeres } \\
4.55 \%\end{array}$ & Hombres \\
\hline Cuéntame & 14 & $14,29 \%$ & $7,14 \%$ & $21,43 \%$ & $64,29 \%$ \\
\hline & 14 & $21,43 \%$ & $50,00 \%$ & $14,29 \%$ & $14,29 \%$ \\
\hline TOTAL & 50 & $24,00 \%$ & $36,00 \%$ & $12,00 \%$ & $30,00 \%$ \\
\hline
\end{tabular}

Si hablamos de la edad de los personajes analizados, observamos que sólo un 4\% del total de cameos se corresponde a mujeres menores de 25 años y un 2\% a hombres de esta franja de edad. Se trata de una franja de edad poco habitual en los cameos, aunque sobre la que recae sobrerrepresentatividad de las mujeres, hecho que nos permite afirmar que las mujeres más jóvenes son más recurrentes como autopromoción que los hombres.

La representación más gruesa es la de hombres y mujeres en términos generales es de 25 a 45 años. La serie Cuéntame, sin embargo, se aleja de la tendencia general. Los hombres de esta franja de edad solo representan un $7,14 \%$ del total de casos, frente al doble de mujeres de esta edad. Este hecho contrasta con los datos de hombres mayores de 45 años, donde destacamos la existencia de 64,29\% de casos destacables. En el caso de colaboraciones con personajes de más de 45 años solo detectamos una representación del $10 \%$ en mujeres, mientas que los hombres de esta franja de edad aparecen en un 30\% de los casos analizados. Por último, cabe destacar la inexistencia de mujeres mayores de 45 años en la serie Fenómenos.

\section{Conclusiones}

En las conclusiones del I Informe del Observatorio de Ficción televisiva de la UNIR se establecía que, $a$ priori, no existía infrarrepresentación en la presencia de mujeres en las series de ficción 
españolas. No obstante, analizando la representación femenina desde el punto de vista de la autopromoción y la autorreferencia publicitaria en un contexto trans e intramediático - en concreto, en forma de cameo- podemos afirmar que la representación de las mujeres es menor que la de los hombres.

Si hablamos del cameo como estrategia de autopromoción de la propia serie podemos decir que se trata de una fórmula explotada en términos generales, de hecho, la alusión por parte del personaje real a la propia cadena o a algún producto en concreto se detecta en un casi un tercio del total de casos analizados. Esta presencia promocional no suele estar vinculada con la autorrepresentación del personaje en la mayoría de casos, con lo que se pierde la oportunidad de dar notoriedad al cameo y convertirlo en fórmula promocional pura, vinculando la ficción con la realidad promocional que acompaña al personaje $\mathrm{y} / \mathrm{o}$ con su posible vinculación prescriptora. No obstante, sí que son utilizados como reclamo para la propia cadena, los propios programas y el propio medio, generando un ciclo de retroalimentaciones que beneficia tanto a la serie como a la compañía y al resto de programas televisivos a los que se hace alusión. En concreto, del estudio sobre las tres series analizadas es posible deducir que el medio televisivo se nutre de sí mismo en la mitad de los casos en los que introduce un cameo en una serie.

Vemos, además, que los cameos generan un discurso trans e intramediático que va más allá de la propia serie y de la propia actuación del personaje y que desarrolla toda una serie de acciones comunicativas y paratextos que contribuyen a promocionar la colaboración del personaje en la serie. En algunos casos la historia se desdobla a través de una relación de espacios intramedial, porque los cameos están protagonizados por personajes que pertenecen a la propia cadena. Pero en términos globales son más comunes los ejemplos de transmedialidad. En este sentido, hemos comprobado cómo las Web de las cadenas se convierten en un elemento clave a la hora de expandir la narrativa. Precisamente es en el caso de las páginas webs de las cadenas y de los espacios dedicados a las propias series donde se han detectado los paratextos intramediáticos más originales.
Siguiendo la clasificación metodológica que se planteó al principio, los cameos asumen el rol familiar y el profesional, cuya representación es distinta entre hombres y mujeres. Destacamos positivamente la representación de mujeres que asumen el rol profesional y aparecen en las narraciones como mujeres independientes incorporadas al mundo laboral, aunque lo cierto es que no se da en la mayoría de los casos, ya que hemos visto que en el caso de las féminas predomina el rol familiar. Resulta curioso, además, que la serie Cuéntame presente mayor índice de mujeres que asumen el rol profesional que hombres, hecho que atribuimos a las necesidades históricas/comunicativas del propio guión de trasmitir un mundo cambiante, aperturista y en el que se empieza a evidenciar la incorporación de la mujer al mundo laboral y la ruptura con las estructuras familiares tradicionales. En cualquier caso, y al margen de las conclusiones específicas de los casos, la representación del rol temático profesional es poco relevante, frente al rol familiar, que tiene mucho más peso en la narración.

En términos generales, la asimilación del rol familiar viene dada por la necesidad de integrar al personaje colaborador en el día a día y las relaciones cotidianas de la ficción. Es muy común que los colaboradores asuman alguna vinculación familiar y se integren (puntualmente) en el seno familiar. En este sentido, resulta destacable la representatividad de los hombres, por ejemplo, en Cuéntame y Fenómenos, en los que (aunque existen colaboraciones profesionales e incluso vinculadas con la autorrepresentación) su presencia enmarcada bajo un rol familiar es mayor que en el caso de las mujeres.

A nivel semiótico, hemos podido observar que el rol de los personajes que actúan mediante la fórmula del cameo son considerados 'buenos' de acuerdo a las acciones que llevan a cabo en el conjunto de la narración, excepto en casos puntuales en los que aparecen para confrontar alguna historia o generar un conflicto o tensión narrativa, pero al fin y al cabo, se trata de una colaboración positiva que busca la vinculación de la realidad con la ficción y no tanto el desarrollo de extensas tramas dramáticas. Asimismo, hemos demostrado que el porcentaje de cameos femeninos con un rol semióticamente 
'bueno' es inferior al masculino. Como aventurábamos en nuestra hipótesis de partida, la figura masculina se relaciona más con lo positivo en términos generales, mientras que la mujer no asimila de forma genérica este rol, sino que sus acciones en este sentido son más cambiantes a lo largo del discurso narrativo.

Desde un punto de vista de género podemos concluir que la mujer es menos predominante en los cameos como fórmula de autopromoción y que se detectan valores arcaicos en la representación femenina, tanto en la vinculación profesional que de ella se deriva, como en la edad de las mismas (mujeres jóvenes e inexpertas frente a hombres maduros y cultivados) Por ejemplo destaca la inexistencia de cameos protagonizados por mujeres mayores de 45 años en la serie Fenómenos.

En definitiva, el cameo como fórmula autopromocional para los productos televisivos se conjuga como todo un discurso publicitario tanto dentro como fuera de la propia ficción. Se convierte, por tanto, en un paratexto que retroalimenta no solo a la serie, sino también a la cadena y al propio colaborador. Se ha podido demostrar que este recurso paratextual presenta diferencias en cuanto al género, ya que la manera en que se representan unos y otros es diferente, inferior en el caso femenino, de la misma manera que se evidencian valores sociales arraigados a los roles tradicionales atribuidos a hombres y mujeres.

\section{Referencias}

- Alemany Zaragoza, E. (2005): Evolución histórica del trabajo de la mujer hasta nuestros días. Discurso de ingreso a la «Reial Academia de Doctores» como académico numerario electo, pronunciado el 14 de diciembre de 2004. Aranzadi, SA, Pamplona. 2005.

- Belmonte, J. y Guillamón, S. (2008): “Coeducar la mirada contra los estereotipos de género en TV”. Comunicar, vol. 31. Universidad de Huelva. Disponbible en: http: / / rabida.uhu.es/dspace/handle/10272/1398 Fecha de consulta: 12 de enero de 2014.

- Bernardo Paniagua, J. $\mathrm{M}^{\mathrm{a}}$, Pellisser, N. y Aguilar Soves, T. (2009). "La construcción de los estereotipos de género en Canal 9: un estudio crítico de L'Alqueria Blanca"

- http: / / www3.udg.edu/publicacions/vell/el ectroni-

ques / congenere / 2 / comunicacions / Jose $\% 20$ Maria $\%$ 20Bernardo.pdf, fecha de consulta: 15 de abril de 2014.

- Brooker, W. (2003): 'Overflow and Audience, in Will Brooker and Deborah Jermyn (eds) The Audience Studies Reader, pp 322-335. London. Routledge.Cambra, C.; Silvestre, N. y Leal, A. (2008): "Función de la subtitulación y la interpretación de la imagen en la comprensión de los mensajes televisivos: la comprensión de una serie por parte de los adolescentes sordos”. Cultura y Educación, nº 1 , vol. 20, no. 1, pp. 81-93(13)

- Chicharro Merayo, M. (2011): "Representaciones juveniles en la ficción televisiva. Los adultos, los jóvenes y la escuela Física y Química”. Doxa Comunicación. $\mathrm{n}^{\mathrm{o}} 14,199-220$

- De Lara González, A.; Rodríguez Ferrándiz, R. y Sánchez Ólmos, C. (2013): "El me-dio en el mensaje: La autorreferencia en la televisión generalista". Pensar la Publicidad. Revista Internacional de Investigaciones Publicitarias. Vol 7, $\mathrm{n}^{\circ} 1$. Universidad Complutense de Madrid .Disponible en: http://bit.ly/1hptm3K Fecha de consulta: 3 de enero 2013

- Diego, P y Grandío, M. (2011): “Clasicismo e innovación en la producción nacional de comedia televisva en España (2000-2010)". Revista Comunicación. $\mathrm{n}^{\mathrm{0}}$ 9, Vol. 1. pp. 49-66.

- Galán Fajardo, E. (2006): “La representación de los inmigrantes en la ficción televisiva en España. Propuesta para un análisis de contenido. El Comisario y Hospital Central.” Revista Latina de Comunicación Social, 61. La Laguna (Tenerife). Disponible en: http:/ / www.ull.es/publicaciones/latina/200608gala n.htmFecha de consulta: 15 de enero de 2014

- García Martínez, A.N. (2009): "El espejo roto: la metaficción en las series anglosajonas". Revista Latina de Comunicación Social, 64, 654-667. La 
Laguna) Tenerife. Universidad de La Laguna. Disponible

en:

http:/ /www.revistalatinacs.org/067art//954_Com plutense/10_GracielaEN.html Fecha de consulta: 10 de enero de 2014.

- García Mirón, S. (2012): "Las emisoras tradicionales frente al desafío de Internet: la integración estratégica de Antena 3". En León, Bienvenido (Coordinador), La televisión ante el desafío de Internet. Salamanca. Comunicación Social.

- Garrido, M. (2007): "La creatividad en la encrucijada sociológica" Revista Creatividad y Sociedad $n^{\circ} 11$ Disponible en

http://www.creatividadysociedad.com/articulos/11 /Creatividad\%20y\%20Sociedad.\%20Estereoti-

pos\%20de\%20g\%C3\%A9nero\%20en\%20la\%20publi cidad.pdf

- Gerbner, G., (1980): "Children and power on television: the other side of the picture". En GERBNER, G., ROSS, CJ.\& ZIGLER, E. (eds.), Child Abuse: an agenda for action. New York: Oxford University Press.

- Gerbner, G.; Gross, L; Signorelli, N \&Morgan, M. (1980): "Aging with Television: Images on Television Drama and Conceptions of Social Reality". Journal of Communication $\mathrm{n}^{\circ} 30$.

- Glascock, J. (2001): "Gender roles on primetime network television: Demographics and behaviours". Journal of Broadcasting\&Electronic Media, $\mathrm{n}^{\circ} 45,656-669$.

- González de Garay, B. (2009):" Ficción online frente a ficción televisiva en la nueva sociedad digital: diferencias de representación del lesbianismo entre las series españolas para televisión generalista y las series para Internet”. Icono 14. Universidad Complutense de Madrid. Disponible en: http://eprints.ucm.es/9856/ Fecha de consulta: 12 de enero de 2014.

- Greenberg, B. S. (1980): Life on television: Content analyses of U.S. TV drama. Norwood, N.J: Ablex Pub. Corp.

- Gunter, B. (1986): Television and sex role stereotyping. London: Libbey.

- Hardy, J. (2011): "Mapping comercial intertextuality: HBO's True Blood. Convergence: The
International Journal of Research into New Media Technologies.

- Harvey, C. B. (2012). "Crossmedia crossstitch: Spinoff stories as transmedial and intramedial suture". En Ibrus, I. y Scolari, C.A. (eds.) (2012). Crossmedia Innovations: Texts, Markets, Institutions. Francfort, Peter Lang, 61-75.

- Jenkins, H. (2006): Convergence Culture. New York: New York University Press

- Lacalle, R. (2010): "Joves i ficció televisiva: representacions i efectes". Revista Anàlisi, no 40, 29 45.

Disponible en:

http://www.raco.cat/index.php/analisi/article/vie wFile/243374/326101 Fecha de consulta: 10 de enero de 2014

- Lair Soto, V. (2011): "La cultura griega hoy". Creación y producción en diseño y comunicación, 107-110, nº 39, Buenos Aires.

- Lauzen, MM; Dozier, DM; Horan, N (2008): "Constructing gender stereotypes through social roles in prime-time television”. Journal of Broadcasting\&Electronic Media n ${ }^{\circ} 52$ (2), 200-214.

- Medina, M. (2007): "Explotación económica de las series familiares de televisión". Comunicación y Sociedad. Vol. XX, Núm. 1, 51-58. Disponible en: http://dspace.si.unav.es/dspace/bitstream/10171/ 8369/1/20090630144134.pdf Fecha de consulta: 10 de enero de 2014

- Morgan, M. (1982): "Television and Adolescent's Sex-Role Stereotypes: A Longitudinal Study”. Journal of Personality and Social Psychology n ${ }^{\circ} 43-5$.

- Padilla-Castillo G. (2012): "Medical television series as a means to educate the public on nutrition and healthy eating". Revista Latina de Comunicación Social, 67, pages 228 to 246. La Laguna) Tenerife. Universidad de La Laguna. Disponible en: http://www.revistalatinacs.org/067art//954_Com plutense/10_GracielaEN.html Fecha de consulta: 10 de enero de 2014

- Perryman, N. (2008): "Doctor Who and the Convergence of Media. A Case of Study in 'Transmedia Storytelling”. Convergence: International Journal of Research into New Media Technologies.

- Ramírez, M. y Cobo, S. (2013): "La ficción gay-friendly en las series de televisión españolas". 
Comunicación y Sociedad, núm. 19. Universidad de Guadalajara. Disponible en: http://bit.ly/1ev0FBV Fecha de consulta: 15 de enero 2014.

- Rodríguez Fidalgo, M.I. y Gallego Santos, $\mathrm{M}^{a}$ del Camino (2012): "Las webs de las series de ficción como nuevas experiencias narrativas en el contexto hipermediático". En León, B. (Coordinador), La televisión ante el desafío de Internet. Salamanca. Comunicación Social.

- Ruiz Collantes, X. et. al. (2006): "La imagen pública de la inmigración en las series de televisión españolas". Polít. cult. [online]., n.26 [citado 2014 02-13], pp. 93-108. Disponible en: http://bit.ly/1d18kXN Fecha de consulta: 10 de enero de 2014

- Sánchez Aranda, J.J, (DIR); Fernández Gömez, E.; Gil Gascón, F y Segado Boj, F. (2001): Las mujeres en la ficción televisiva española de prime time (I Informe del Observatorio Audiovisual de Identidades de la Universidad Internacional de La Rioja). Logroño: Universidad Internacional de La Rioja.
- Scolari, C.A. (2009): "Transmediastorytelling: Implicitconsumers, narrativeworlds, and branding in contemporary media production”. International Journal of Communication $n^{\circ}$ 3: 586-606 Descargar de: http://bit.ly/MBaR0h Fecha de consulta: 15 de enero de 2014

- Van Dijk, T.A (2008): "Semántica del discurso e ideología". Discurso \& Sociedad, vol 2(1), 201 261. Disponible en: http:/ / www.dissoc.org/ediciones/v02n01/DS2\%28 1\%29Van\%20Dijk.pdf. Fecha de consulta: 08 de enero de 2014.

- Van Heerden, B. (1998): Film and Television in-Jokes: Nearly 2,000 IntentionalReferences, Parodies, Allusions, Personal Touches, Cameos, Spoofs, and Homages. Jefferson, NC: McFarland.

- Wernick, A. (1991): Promotional Culture. Londres: Sage.

\begin{abstract}
Apoyos
Este estudio se realiza en el marco del proyecto $\mathrm{I}+\mathrm{D}+\mathrm{i}$ La construcción social de la mujer en la ficción televisiva y la web 2.0: prototipos, recepción y retroalimentación con referencia FEM2012-33411 dirigido por la Dra. Rosario Lacalle Zalduendo (UAB) financiado por el Ministerio de Economía y Competitividad (España).
\end{abstract}

\title{
Forma de Citación
}

DE LARA GONZÁLEZ, Alicia y HIDALGO-MARÍ, Tatiana: El cameo en las series de televisión españolas desde una perspectiva de género: Un recurso de narrativa transmedia e intramedia. Revista Communication Papers, $N^{\circ} 4$, páginas 37 a 51. Departamento de Filología y Comunicación de la Universidad de Girona. Recuperado el __ de de 2 de: http://www.communicationpapers.es 